\title{
REMEDIATION OF $\mathrm{CO}_{2}$ IN BOUDOUARD'S REACTION AS AN EXAMPLE OF REVERSIBLE CHEMICAL REACTION
}

\begin{abstract}
One of the fundamental elements of a scientist's work is the ability to lead observations of the phenomena that surround us and based on them making conclusions. These observations are conducted within the so-called scientific experiments. Lessons learned based on the results obtained in experiments allow researchers to better understand the essence of the phenomena occurring in the world around us. Drawing conclusions is not always easy. In order to achieve this skill, we must possess a well-established knowledge in the field of the phenomenon that interests us. The most striking example of how important skills are observation and drawing proper conclusions is the phenomenon of global climate warming. The main parameter influencing temperatures registered on Earth is the concentration of greenhouse gases in the atmosphere, and especially carbon dioxide created from combustion processes. A significant role in studies of the reduction of $\mathrm{CO}_{2}$ emissions plays chemists. To be sure that conducted by them experiments are optimally designed, it is necessary to ensure them with proper education already at the secondary school level. The main aim of this article was to conduct the study in order to explain chemical issues that create the greatest cognitive difficulties among students. The second aim of the article was to propose a chemical experiment to students that would allow them to find out more about the phenomena governing in the area of problematic issues. The proposed experiment is based on the concept of solubility equilibrium. Results of preliminary tests that have been carried out after applying this experiment on a small group of students, indicated their better understanding of the studied subject.
\end{abstract}

Keywords: Boudouard reaction, equilibrium constant, inquiry-based science education, chemical experiment

\section{Introduction}

Since 1988, employees of Chemical Education Department of the Faculty of Chemistry of the Jagiellonian University have been organizing the Chemical Knowledge Competition for secondary school students. In Poland, studying in secondary schools lasts 3 years and ends with an secondary school-leaving examination. One of the subjects that the students may pass during this exam is chemistry at an extended level. The competition is intended for the second and third grade students from secondary schools of Malopolska Province. Each school year approximately 1300 students take part in the competition. The aim of the competition is to encourage students to be interested in chemistry and enable them to test their knowledge. The scope of material and the formula of the competition tasks were changed in 2014. At present, the competition sheet contains 5 single-choice and 5 multiple-choice tasks, 3 Lowson tasks and 3 open-ended tasks (Fig. 1).

\footnotetext{
${ }^{1}$ Faculty of Chemistry, Jagiellonian University, ul. Gronostajowa 2, 30-387 Kraków, Poland, phone +48126862454

*Corresponding author: elzbieta.szostak@uj.edu.pl
} 


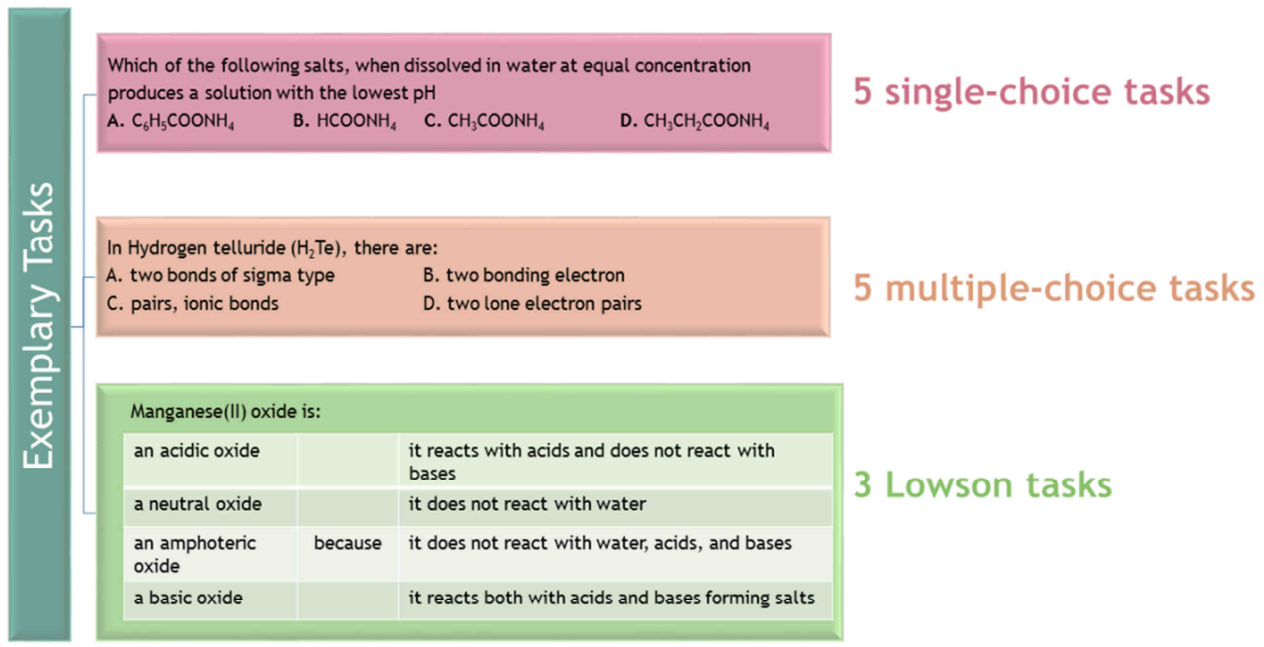

Plus 3 open-ended tasks

Fig. 1. Exemplary closed tasks from the competition sheet

Students' answers are analysed. On this basis, the most difficult issues for students are chosen and next elaborated in order to create of new methodological solutions. These solutions are presented to teachers and students [1].

\section{Data analysis}

Based on all the answers given by the third-grade students of general secondary schools, who have participated in the Chemical Knowledge Competition, the tasks with the greatest index of the wrong answers were selected and next analysed in terms of difficulties faced by students during solving the problem. The research covered 500 competition contestants (337 females and 163 males). It turned out that the biggest challenge for pupils was to answer the questions about the equilibrium established in the system during the so-called Boudouard reaction [2]. Therefore, only these tasks were the subject of further analysis. Boudouard reaction takes place during the gasification of coal and other carbon-rich sources and is very important due to the possibility remediation of $\mathrm{CO}_{2}$ by reducing it to carbon monoxide, which can be next used to produce hydrogen [3]. The analysis covered only the competition tasks checking the knowledge contained in the following points of the core curriculum:

Student:

- demonstrates the knowledge and understanding of the following concepts: the state of dynamic equilibrium (balance) and equilibrium constant; writes the equilibrium constant expression of a given reaction;

- applies Le Chatelier's principle to the qualitative determination of the impact of change in temperature, concentration of reagents and pressure on the system in a state of dynamic equilibrium. 


\section{Results of data analysis}

The subject of the analysis were students' answers given to the following competition questions:

\section{Problem 1:}

Gaseous carbon monoxide can be obtained by reducing carbon dioxide using elemental carbon.

1a. Assuming that this reaction is reversible one and the system is at equilibrium state, write down the equation of this reaction and equilibrium constant $\left(K_{c}\right)$ expression for this reaction.

1b. State whether the following sentences are true or false.

\begin{tabular}{|c|c|c|c|}
\hline No. & Question & True & False \\
\hline I & $\begin{array}{c}\text { The efficiency of the reaction will increase if the pressure in } \\
\text { the system increases. }\end{array}$ & & \\
\hline II & $\begin{array}{c}\text { Increasing the amount of carbon in the reaction vessel will } \\
\text { shift the equilibrium of the reaction to the right. }\end{array}$ & & \\
\hline
\end{tabular}

Table 1 presents the results of the statistical analysis of the data obtained based on the answers provided by students in competition sheets.

On the basis of the obtained results we can conclude that there were no clear differences between answers given by female and male contestants. As the conducted analysis indicated, writing down the equation of chemical reaction occurring in the given system was not a problem for the students, however, as many as $1 / 3$ of them forgot to mark the state of chemical equilibrium by appropriately written arrows. Difficulties encountered by students in distinguishing between complete and incomplete chemical transformations have already been reported in several works [4-9]. This proves a strong need for a wider explanation of equilibrium processes to pupils.

About half of all respondents were able to write correctly the expression for $K_{c}$. More than $1 / 3$ of the rest added the concentration of solid carbon to this expression, which is in a different phase than the other reagents. On average, every tenth student was not able to write down the correct expression for the equilibrium constant. Additionally, nine out of ten those students, who wrote down correctly the expression for the equilibrium constant $K_{c}$ or input the concentration of carbon into it, answered correctly the question about influence of the pressure changes on the system state. The correct answer to this question was also given by every second student who could not write down the proper expression for $K_{c}$. In turn, the most difficult question for participants of the competition was the question about influence of change in the amount of the solid component on the efficiency of the reaction.

As our previous observations have shown, students have no problems with questions concerning single-phase multi-component systems. However, finding correct answer to the question about the equilibrium state in multi-phase multi-component systems causes problem for the majority of them. On the basis of the results obtained, a conclusion can be drawn about a need for designing a chemical experiment that will help pupils understand the essence of the problematic phenomenon. As research indicates, the best way to understand the problem is its visualization [10]. Thus, in the further part of this work we 
proposed the laboratory classes that would help pupils to understand that addition of solids to the system being in equilibrium state does not affect the efficiency of reaction/process.

Table 1

Results of the statistical data analysis obtained on the basis of the answers given

by participants of Chemical Knowledge Competition

\begin{tabular}{|c|c|c|c|c|c|}
\hline \multicolumn{2}{|c|}{$\begin{array}{l}\text { The number of students who } \\
\text { correctly wrote down the equation of } \\
\text { the chemical reaction, remembering } \\
\text { to mark the equilibrium state by two } \\
\text { arrows pointing in the opposite } \\
\text { directions }\end{array}$} & \multicolumn{2}{|c|}{$\begin{array}{l}\text { The number of students who wrote } \\
\text { down the equation of the chemical } \\
\text { reaction correctly, but did not mark } \\
\text { the equilibrium state by two arrows } \\
\text { pointing in the opposite directions }\end{array}$} & \multicolumn{2}{|c|}{$\begin{array}{l}\text { The number of students who wrote } \\
\text { down the equation of the chemical } \\
\text { reaction incorrectly }\end{array}$} \\
\hline Female $(N=337)$ & Male $(N=163)$ & Female $(N=337)$ & Male $(N=163)$ & Female $(N=337)$ & Male $(N=163)$ \\
\hline $\begin{array}{c}196 \\
58 \% \\
\end{array}$ & $\begin{array}{c}109 \\
67 \% \\
\end{array}$ & $\begin{array}{c}131 \\
39 \% \\
\end{array}$ & $\begin{array}{c}50 \\
31 \% \\
\end{array}$ & $\begin{array}{c}10 \\
3 \% \\
\end{array}$ & $\begin{array}{c}4 \\
2 \%\end{array}$ \\
\hline \multicolumn{2}{|c|}{$\begin{array}{l}\text { The number of students who wrote } \\
\text { the equilibrium expression for } K_{c} \text { as } \\
\text { follows: } \\
\qquad K_{c}=\frac{[\mathrm{CO}]^{2}}{\left[\mathrm{CO}_{2}\right]}\end{array}$} & \multicolumn{2}{|c|}{$\begin{array}{l}\text { The number of students who wrote } \\
\text { the equilibrium expression for } K_{c} \text { as } \\
\text { follows: } \\
\qquad K_{c}=\frac{[\mathrm{CO}]^{2}}{\left[\mathrm{CO}_{2}\right] \cdot[\mathrm{C}]}\end{array}$} & \multicolumn{2}{|c|}{$\begin{array}{l}\text { The number of students who gave } \\
\text { other wrong answers to this question }\end{array}$} \\
\hline Female $(N=327)$ & Male $(N=159)$ & Female $(N=327)$ & Male $(N=159)$ & Female $(N=327)$ & Male $(N=159)$ \\
\hline $\begin{array}{c}177 \\
54 \% \\
\end{array}$ & $\begin{array}{c}87 \\
55 \% \\
\end{array}$ & $\begin{array}{c}124 \\
38 \% \\
\end{array}$ & $\begin{array}{c}49 \\
31 \% \\
\end{array}$ & $\begin{array}{c}26 \\
8 \% \\
\end{array}$ & $\begin{array}{c}23 \\
14 \% \\
\end{array}$ \\
\hline \multicolumn{2}{|c|}{$\begin{array}{l}\text { The number of students who wrote } \\
\text { the } K_{c} \text { properly, and answered } \\
\text { correctly to the question } 1 \mathrm{bI}\end{array}$} & \multicolumn{2}{|c|}{$\begin{array}{l}\text { The number of students who inserted } \\
\text { the concentration of the carbon into } \\
\text { the } K_{c} \text { expression but answered } \\
\text { correctly to the question } 1 \mathrm{bI}\end{array}$} & \multicolumn{2}{|c|}{$\begin{array}{l}\text { The number of students who wrote } \\
\text { the wrong expression for } K_{c} \text { but } \\
\text { answered correctly to the question } \\
\text { 1bI }\end{array}$} \\
\hline Female $(N=177)$ & Male $(N=87)$ & Female $(N=124)$ & Male $(N=49)$ & Female $(N=36)$ & Male $(N=27)$ \\
\hline $\begin{array}{c}158 \\
89 \%\end{array}$ & $\begin{array}{c}80 \\
92 \%\end{array}$ & $\begin{array}{c}100 \\
81 \%\end{array}$ & $\begin{array}{c}41 \\
87 \%\end{array}$ & $\begin{array}{c}22 \\
61 \%\end{array}$ & $\begin{array}{c}14 \\
52 \%\end{array}$ \\
\hline \multicolumn{2}{|c|}{$\begin{array}{c}\text { The number of students who wrote } \\
\text { the } K_{c} \text { properly, and answered } \\
\text { correctly to the questions } 1 \mathrm{bI} \text { and } \\
1 \text { bII }\end{array}$} & \multicolumn{2}{|c|}{$\begin{array}{l}\text { The number of students who inserted } \\
\text { the concentration of the carbon into } \\
\text { the } K_{c} \text { expression, answered correctly } \\
\text { to the question } 1 \mathrm{bI} \text {, but answered } \\
\text { incorrectly to the question } 1 \mathrm{bII}\end{array}$} & \multicolumn{2}{|c|}{$\begin{array}{l}\text { The number of students from the } \\
\text { whole group of the competition } \\
\text { participants of a given sex who } \\
\text { answered correctly to the questions } \\
\text { 1a and 1bI }\end{array}$} \\
\hline Female $(N=158)$ & Male $(N=80)$ & Female $(N=100)$ & Male $(N=41)$ & Female $(N=337)$ & Male $(N=163)$ \\
\hline \multirow{4}{*}{$\begin{array}{c}22 \\
14 \%\end{array}$} & \multirow{4}{*}{$\begin{array}{c}27 \\
34 \%\end{array}$} & \multirow{4}{*}{$\begin{array}{c}95 \\
95 \%\end{array}$} & \multirow{4}{*}{$\begin{array}{c}40 \\
98 \%\end{array}$} & $\begin{array}{c}107 \\
32 \% \\
\end{array}$ & $\begin{array}{c}56 \\
34 \% \\
\end{array}$ \\
\hline & & & & \multicolumn{2}{|c|}{$\begin{array}{l}\text { The number of students from the } \\
\text { whole group of the competition } \\
\text { participants of a given sex who } \\
\text { answered correctly to all the } \\
\text { questions }\end{array}$} \\
\hline & & & & Female $(N=337)$ & Male $(N=163)$ \\
\hline & & & & $\begin{array}{c}15(21) \\
5 \% \\
\end{array}$ & $\begin{array}{c}19 \\
12 \%\end{array}$ \\
\hline
\end{tabular}

\section{Background}

In any saturated solution that stays in contact with the solid phase of dissolved substance, a state of dynamic equilibrium is established between the substance in the solution and its sediment (in a unit of time the same number of ions goes from the solid phase to the solution as (the number of ions) deposits on the surface of the crystal) $[11,12]$. In the experiment proposed below this equilibrium can be described by the equation: 


$$
\mathrm{CuCl}_{2(s)} \rightleftarrows \mathrm{Cu}_{(a q)}^{2+}+2 \mathrm{Cl}_{(a q)}^{-}
$$

The equilibrium constant for this reaction is expressed as follows:

$$
K_{c}=\left[\mathrm{Cu}^{2+}\right] \cdot\left[\mathrm{Cl}^{-}\right]^{2}
$$

(simplifying assumptions: the activities of the ions and the ionic strength of the solution are not considered).

Using Le Chatelier's principle in reference to such a reaction, it can be predicted how addition of solid $\mathrm{CuCl}_{2}$ salt or the concentration change of one of the ions affect the efficiency of precipitation of the sediment in the system. These predictions can be next verified based on the proposed chemical experiment.

\section{Experimental procedure}

The core of the experiment:

Reagents

1. Saturated solutions of $\mathrm{CuCl}_{2}, \mathrm{CuSO}_{4}$ and $\mathrm{K}_{2} \mathrm{SO}_{4}$ (prepared by dissolving solid salts of $\mathrm{CuCl}_{2} \cdot 2 \mathrm{H}_{2} \mathrm{O}, \mathrm{CuSO}_{4} \cdot 5 \mathrm{H}_{2} \mathrm{O}$, and $\mathrm{K}_{2} \mathrm{SO}_{4}$ in distilled water)

2. Concentrated $\mathrm{HCl}$ acid

\section{Titration of copper ions}

Reagents

1. 0.01 M EDTA

2. Indicator: murexide

Titration of chloride ions

1. $0.1 \mathrm{M} \mathrm{AgNO}_{3}$

2. $0.1 \mathrm{M} \mathrm{KSCN}$

3. $(1+1, \mathrm{v} / \mathrm{v}) \mathrm{HNO}_{3}$

4. Indicator: $10 \%$ solution of ammonium iron(III) sulphate dodecahydrate $\left(\mathrm{NH}_{4} \mathrm{Fe}\left(\mathrm{SO}_{4}\right)_{2} \cdot 12 \mathrm{H}_{2} \mathrm{O}\right)$ in nitric acid

5. Chloroform

\section{Preparation of reagents}

1. Prepare $300 \mathrm{~cm}^{3}$ of saturated solutions of $\mathrm{CuCl}_{2}, \mathrm{CuSO}_{4}$ and $\mathrm{K}_{2} \mathrm{SO}_{4}$ by dissolving the excess of the corresponding salt or its hydrate in $300 \mathrm{~cm}^{3}$ of distilled water.

2. Prepare standard solutions of $\mathrm{AgNO}_{3}$ and $\mathrm{KSCN}$ from fixanal ampoules.

3. Prepare $0.01 \mathrm{M}$ EDTA solution by dissolving $3.7224 \mathrm{~g}$ of $\mathrm{Na}_{2}$ EDTA $\cdot 2 \mathrm{H}_{2} \mathrm{O}$ into a $1 \mathrm{dm}^{3}$ volumetric flask containing about $300 \mathrm{~cm}^{3}$ of distilled water and fill up to the mark the resulting solution with distilled water.

4. Weigh out about $5 \mathrm{~g}$ of $\mathrm{FeNH}_{4}\left(\mathrm{SO}_{4}\right)_{2} \cdot 12 \mathrm{H}_{2} \mathrm{O}$. Grind the salt in a mortar to a fine powder. Mix $4 \mathrm{~g}$ of this salt with $40 \mathrm{~cm}^{3}$ of distilled water and a few drops of concentrated nitric acid.

5. All the other reagents i.e. concentrated solutions of $\mathrm{HCl}$ and $\mathrm{HNO}_{3}$, solid salts, murexide and chloroform may be purchased directly from Sigma-Aldrich. 


\section{Idea of the experiment}

The experiment presented here was designed for a group of maximum 16 students. The experiment requires two 4-5 hour lab sessions. In the first part of the experiment students, by means of a pipette, transfer each time $1 \mathrm{~cm}^{3}$ of saturated $\mathrm{CuCl}_{2}$ solution into four separate Petri dishes. Next, students add into the first Petri dish $1 \mathrm{~cm}^{3}$ of concentrated $\mathrm{HCl}$, into the second one $1 \mathrm{~cm}^{3}$ of saturated $\mathrm{CuSO}_{4}$ solution, into the third one $1 \mathrm{~cm}^{3}$ of saturated $\mathrm{K}_{2} \mathrm{SO}_{4}$, and into the fourth one a small amount (ca. $650 \mathrm{mg}$ ) of solid $\mathrm{CuCl}_{2} \cdot 2 \mathrm{H}_{2} \mathrm{O}$. After that part, they write down their observations into the lab notebooks.

In the second part of the experiment, students pour prepared earlier saturated $\mathrm{CuCl}_{2}$ solution into four separate test tubes. Next, they add $2 \mathrm{~cm}^{3}$ of concentrated hydrochloride acid to the second tube, $2 \mathrm{~cm}^{3}$ of saturated $\mathrm{CuSO}_{4}$ solution to the third tube, and $650 \mathrm{mg}$ of solid $\mathrm{CuCl}_{2} \cdot 2 \mathrm{H}_{2} \mathrm{O}$ to the fourth tube. The first test tube should contain only a clear saturated $\mathrm{CuCl}_{2}$ solution. The main aim of this experiment is determination of the contents of $\mathrm{Cu}^{2+}$ and $\mathrm{Cl}^{-}$ions in each of the four test tubes.

In turn, during titration experiment students work in pairs. In the first step during the first lab period, one of the students (Student 1) determines the content of $\mathrm{Cu}^{2+}$ ions, and the other student (Student 2) determines the content of $\mathrm{Cl}^{-}$ions in the first test tube. In the second step during the second lab period students exchange their research places. From that moment Student 1 determines the content of $\mathrm{Cl}^{-}$ions in the third and fourth test tube, and Student 2 determines the content of $\mathrm{Cu}^{2+}$ ions in the second and fourth test tube. To determine the contents of $\mathrm{Cu}^{2+}$ and $\mathrm{Cl}^{-}$ions in individual tubes, before titration, each of the tested solutions needs to be diluted with distilled water by dissolving $1 \mathrm{~cm}^{3}$ of the tested solution into a $1 \mathrm{dm}^{3}$ volumetric flask.

Titration of $\mathrm{CuCl}_{2}$ solution with EDTA (determination of $\mathrm{Cu}^{2+}$ concentration)

The chemical reaction of complexation occurring between the sample and titrant:

$\mathrm{Cu}^{2+}{ }_{(a q)}+(\mathrm{EDTA})^{2-}{ }_{(a q)} \rightarrow \mathrm{Cu}\left(\mathrm{EDTA}^{2-}{ }_{(a q)}+2 \mathrm{H}^{+}{ }_{(a q)}\right.$

1. Rinse the burette first with distilled water, then with small amount of $0.01 \mathrm{~mol} / \mathrm{dm}^{3}$ $\mathrm{Na}_{2}$ EDTA $2 \mathrm{H}_{2} \mathrm{O}$ titrant solution and finally fill it up with this solution. Record the initial volume to 1 decimal place.

2. Transfer precisely $25.00 \mathrm{~cm}^{3}$ of diluted solution of copper(II) chloride into a clean conical flask using a pipette.

3. Titrate each sample with the standardized EDTA solution (do not forget about constant stirring of titrated solution during the experiment). To see better the endpoint of titration, put a white sheet of paper under the conical flask with titrated solution. Near the endpoint the light yellow solution turns green and then suddenly converts into purplish blue. This moment is the endpoint of the titration (Fig. 2).

4. Record the burette reading.

5. Repeat the titration (procedure 2-4) for one more $25.00 \mathrm{~cm}^{3}$ sample.

6. Calculate the mass in grams and concentration of copper ions in moles of diluted solution using the following equations:

$$
\begin{gathered}
m_{\mathrm{Cu}}=c_{\mathrm{EDTA}} \cdot 63.53 \cdot 40[\mathrm{~g}] \\
n_{\mathrm{Cu}}=\frac{m_{\mathrm{Cu}}}{63.53}[\mathrm{~mol}]
\end{gathered}
$$




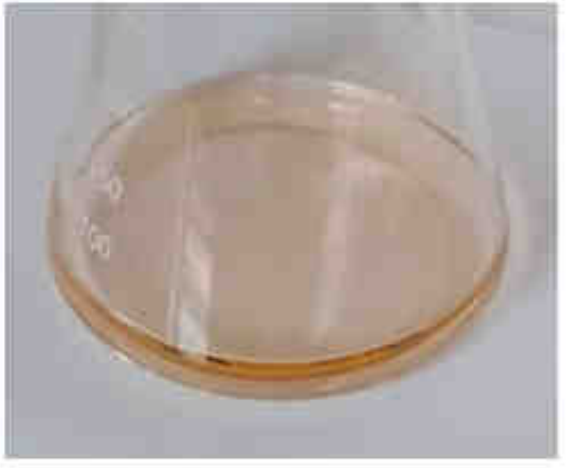

light yellow solution

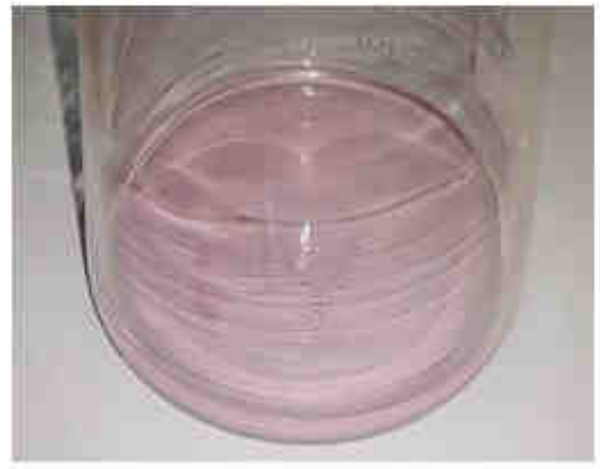

purplish blue solution

Fig. 2. Colours of the studied solution before and at the endpoint of titration of $\mathrm{CuCl}_{2}$ with EDTA

Titration of $\mathrm{CuCl}_{2}$ solution by Volhard's method (determination of $\mathrm{Cl}^{-}$concentration)

The chemical reactions occurring during titration:

$\mathrm{Ag}_{(a q)}^{+}+\mathrm{Cl}_{(a q)}^{-} \rightarrow \mathrm{AgCl}_{(s)}$

$\mathrm{Ag}^{+}(a q)+\mathrm{SCN}_{(a q)}^{-} \rightarrow \mathrm{AgSCN}_{(s)}$

$\mathrm{Fe}^{3+}{ }_{(a q)}+\mathrm{SCN}_{(a q)}^{-} \rightarrow[\mathrm{Fe}(\mathrm{SCN})]^{2+}{ }_{(a q)}$ white precipitate

white precipitate

dark red complex ion

KSCN titrant solution and finally fill it up with this solution. Record the initial volume to 1 decimal place.

2. Transfer precisely $25.00 \mathrm{~cm}^{3}$ of diluted copper(II) chloride solution into a clean conical flask using a pipette.

3. Measure $5 \mathrm{~cm}^{3}$ of $(1+1, \mathrm{v} / \mathrm{v}) \mathrm{HNO}_{3}$ acid using a graduated cylinder, place it in the conical flask and then dilute this solution with distilled water to about $50 \mathrm{~cm}^{3}$.

4. Using a pipette transfer $25.00 \mathrm{~cm}^{3}$ of standard $\mathrm{AgNO}_{3}$ solution into the conical flask.

5. Under the ventilated hood add at first $3 \mathrm{~cm}^{3}$ of chloroform and then $1 \mathrm{~cm}^{3}$ of ammonium iron(III) sulphate to the tested solution using graduated cylinders.

6. Stir the obtained solution in the horizontal position for one minute to precipitate white coloured silver chloride.

7. Titrate the unreacted silver ions with the potassium thiocyanate solution. The endpoint of this titration is the first appearance of creamy-beige colour associated with the presence of a $[\mathrm{Fe}(\mathrm{SCN})]^{2+}$ ions and white $\mathrm{AgCl}$ precipitate in the solution (see Fig. 3).

8. Record the burette reading.

9. Repeat the titration (procedure 2-8) for one more $25.00 \mathrm{~cm}^{3}$ sample.

10. Calculate the mass in grams and concentration of chlorine ions in moles of diluted solution using following equations:

$$
\begin{gathered}
m_{\mathrm{Cl}}=\frac{\left(V_{\mathrm{AgNO}_{3}} \cdot c_{\mathrm{AgNO}_{3}}-V_{\mathrm{KSCN}} \cdot c_{\mathrm{KSCN}}\right) \cdot 35.46 \cdot 40}{1000}[\mathrm{~g}] \\
n_{\mathrm{Cu}}=\frac{m_{\mathrm{Cu}}}{35.46}[\mathrm{~mol}]
\end{gathered}
$$


a)

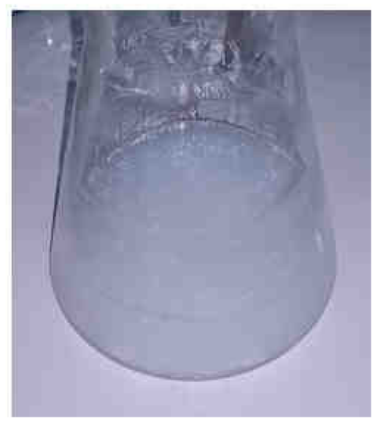

white precipitate of $\mathrm{AgCl}$ b)

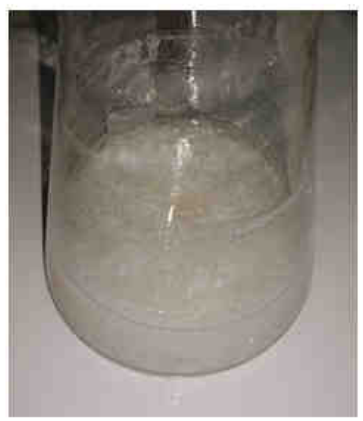

endpoint c)

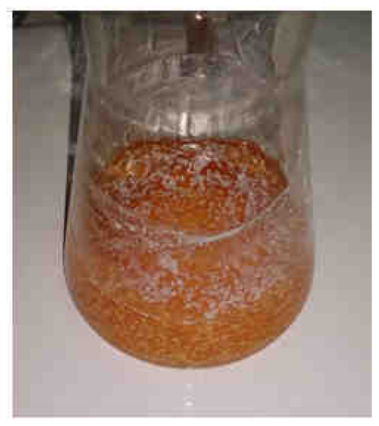

dark red precipitate of $\mathrm{AgSCN}$

Fig. 3. Colours of the studied solution during titration of $\mathrm{CuCl}_{2}$ by Volhard's method: a) before the endpoint, b) when the endpoint has been reached, and c) after the endpoint of titration

\section{Hazards}

$\mathrm{Cu}(\mathrm{II})$ salts, whether in a solid state or in solution, have acute toxicity on oral and dermal tissues and can cause irritation to skin, eyes and the respiratory tract $[13,14]$. It is necessary to avoid breathing dust, fumes, mist, vapours, or spray of copper(II) sulphate or copper(II) chloride. $\mathrm{HCl}$ and $\mathrm{HNO}_{3}$ concentrated acids have a corrosive effect on human skin $[15,16]$. The vapours irritate the respiratory system, eyes, and other mucous membranes. A brief exposure to the solutions of $\mathrm{AgNO}_{3}$ and $\mathrm{K}_{2} \mathrm{SO}_{4}$ will not produce any immediate side effects other than the purple, brown or black stains on the skin, which are created as a result of an oxidizing properties of $\mathrm{AgNO}_{3}$. Upon a constant exposure of these agents, the side effects including irritation to skin, eyes, and the respiratory tract will be noticeable [17-19]. KSCN is harmful if swallowed or inhaled, and causes irritation to skin, eyes, and the respiratory tract [20]. Chloroform causes moderate eye and skin irritation on contact. Prolonged contact may cause poisoning even through intact skin. Ingestion causes nausea, vomiting, diarrhea, and liver and heart damage [21]. To minimize exposure to chloroform it should be added to the titrated solution under a well ventilated hood. Also, although chloroform is not flammable, it can produce toxic fumes when exposed to flame. Thus, care should be taken to eliminate open flames near areas where chloroform is being used. Personal protective equipment such as goggles and protective gloves should be required to wear to minimize risks throughout the experiment. In case of contact of concentrated solutions with skin or eyes, students should wash the affected area with water immediately. When finished, the remaining solutions should not be drained into the sink; they must be collected into the marked bottles and then properly utilized.

\section{Results of experiment and discussion}

In the first part of the experiment a qualitative study was carried out involving the observation of changes taking place in a saturated solution of $\mathrm{CuCl}_{2}$ after adding to it $1 \mathrm{~cm}^{3}$ of four reagents: concentrated acid $\mathrm{HCl}_{(\text {conc) }}$, saturated solutions of $\mathrm{CuSO}_{4(\text { sat })}$ and $\mathrm{K}_{2} \mathrm{SO}_{4(s a t)}$, and solid $\mathrm{CuCl}_{2} \cdot 2 \mathrm{H}_{2} \mathrm{O}$, respectively. The results of this experiment was shown in Figure 4. 
a)
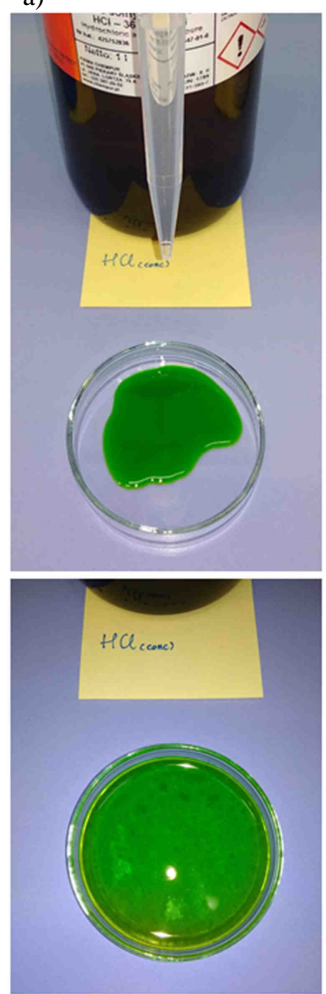

Fig. 4. Observations of changes taking place in a saturated solution of $\mathrm{CuCl}_{2}$ after introducing to it:

a) $\mathrm{HCl}_{(\text {conc })}$, b) $\mathrm{CuSO}_{4(\text { sat })}$, c) $\mathrm{K}_{2} \mathrm{SO}_{4(\text { sat })}$, and d) solid $\mathrm{CuCl}_{2} \cdot 2 \mathrm{H}_{2} \mathrm{O}$

d)
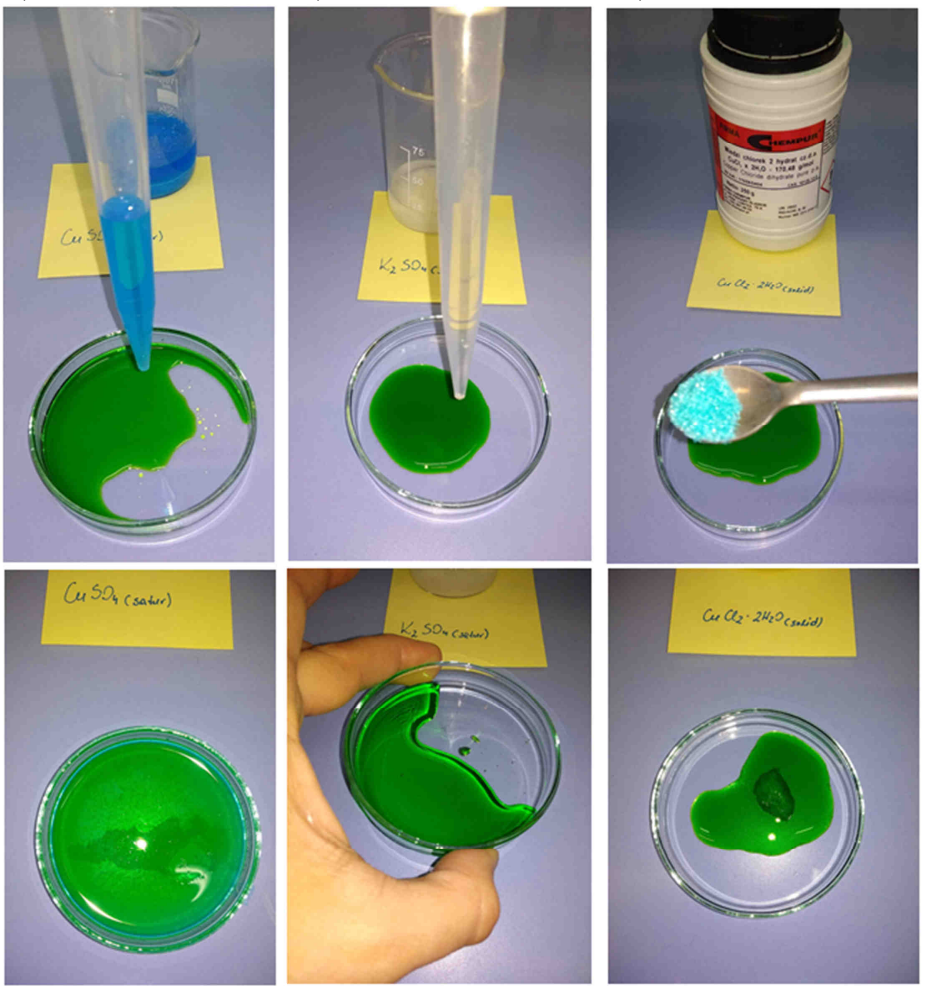

Determination of $\mathrm{Cu}^{2+}$ ions concentration in solution

Table 2

\begin{tabular}{|c|c|c|c|c|c|}
\hline Mixture & $\underset{\left[\mathbf{m o l}^{\prime} / \mathbf{d m}^{3}\right]}{c_{\text {EDTA }}}$ & $\begin{array}{l}V_{\text {EDTA }} \\
{\left[\mathrm{cm}^{3}\right]}\end{array}$ & $\begin{array}{c}\text { Mass of } \mathrm{Cu}^{2+} \\
\text { in } 1 \mathrm{dm}^{3} \text { of the tested } \\
\text { solution } \\
{\left[\mathrm{g} / \mathrm{dm}^{3}\right]}\end{array}$ & $\begin{array}{c}\text { Number of copper ions } \\
\text { moles in } 1 \mathrm{dm}^{3} \text { of the } \\
\text { tested solution } \\
{\left[\mathrm{mol} / \mathrm{dm}^{3}\right]}\end{array}$ & $\begin{array}{c}\text { Concentration of } \\
\mathrm{CuCl}_{2} \text { in the tested } \\
\text { solution } \\
{\left[\mathrm{mol} / \mathrm{dm}^{3}\right]}\end{array}$ \\
\hline $\begin{array}{c}\text { Pure } \mathrm{CuCl}_{2} \\
\text { saturated solution }\end{array}$ & \multirow{3}{*}{0.01} & 12.4 & 315 & 4.96 & 4.96 \\
\hline $\begin{array}{l}\text { Saturated solution } \\
\text { of } \mathrm{CuCl}_{2} \text { with } \\
\text { addition of } 2 \mathrm{~cm}^{3} \\
\text { of concentrated } \\
\text { solution of } \mathrm{HCl}\end{array}$ & & 9.80 & 249 & 3.92 & 3.92 \\
\hline $\begin{array}{c}\text { Saturated solution } \\
\text { of } \mathrm{CuCl}_{2} \text { with } \\
\text { addition of } \\
300 \mathrm{mg} \text { of solid } \\
\mathrm{CuCl}_{2} \cdot 2 \mathrm{H}_{2} \mathrm{O}\end{array}$ & & 12.4 & 315 & 4.96 & 4.96 \\
\hline
\end{tabular}


As can be seen in Figure 4 addition of concentrated $\mathrm{HCl}$ acid or saturated $\mathrm{CuSO}_{4}$ solution into the Petri dishes with saturated $\mathrm{CuCl}_{2}$ solution caused immediate precipitation of the copper(II) chloride sediment. This phenomenon was not observed in Petri dishes with the $\mathrm{CuCl}_{2 \text { (sat) }}$ solutions after addition into them the saturated solution of $\mathrm{K}_{2} \mathrm{SO}_{4}$ or solid $\mathrm{CuCl}_{2} \cdot 2 \mathrm{H}_{2} \mathrm{O}$ salt.

The second part of the experiment included the quantitative indication of changes occurring in the $\mathrm{CuCl}_{2}$ saturated solution under the influence of the disturbance of existing in it equilibrium state. The results of titration of $\mathrm{CuCl}_{2}$ saturated solution before and after adding to it concentrated $\mathrm{HCl}$ acid and saturated $\mathrm{CuSO}_{4}$ solution were presented in Tables 2 and 3. Calculations were made according to equations (3)-(4) and (5)-(6), respectively.

Table 3

Determination of $\mathrm{Cl}^{-}$ions concentration in solution

\begin{tabular}{|c|c|c|c|c|c|}
\hline Mixture & $\begin{array}{c}\text { Constant } \\
\text { parameters of } \\
\text { titration }\end{array}$ & $\begin{array}{l}V_{\mathrm{KSCN}} \\
{\left[\mathrm{cm}^{3}\right]}\end{array}$ & $\begin{array}{c}\text { Mass of } \mathrm{Cl}^{-} \text {in } \\
1 \mathrm{dm}^{3} \text { of the } \\
\text { tested solution } \\
{\left[\mathrm{g} / \mathrm{dm}^{3}\right]}\end{array}$ & $\begin{array}{c}\text { Number of Cl- } \\
\text { moles in } 1 \mathrm{dm}^{3} \text { of } \\
\text { the tested solution } \\
{\left[\mathrm{mol} / \mathbf{d m}^{3}\right]}\end{array}$ & $\begin{array}{l}\text { Concentration of } \\
\mathrm{CuCl}_{2} \text { in the } \\
\text { tested solution } \\
{\left[\mathrm{mol} / \mathrm{dm}^{3}\right]}\end{array}$ \\
\hline $\begin{array}{l}\text { Pure } \mathrm{CuCl}_{2} \text { saturated } \\
\text { solution }\end{array}$ & \multirow{3}{*}{$\begin{aligned} c_{\mathrm{AgNO}_{3}} & =0.1 \mathrm{M} \\
V_{\mathrm{AgNO}_{3}} & =25 \mathrm{~cm}^{3} \\
c_{\mathrm{KSCN}} & =0.1 \mathrm{M}\end{aligned}$} & 22.5 & 355 & 10.0 & 5.00 \\
\hline $\begin{array}{c}\text { Saturated solution of } \\
\mathrm{CuCl}_{2} \text { with addition of } \\
2 \mathrm{~cm}^{3} \text { of concentrated } \\
\text { solution of } \mathrm{CuSO}_{4}\end{array}$ & & 23.6 & 199 & 5.60 & 2.80 \\
\hline $\begin{array}{l}\text { Saturated solution of } \\
\mathrm{CuCl}_{2} \text { with addition of } \\
300 \mathrm{mg} \text { of solid } \\
\mathrm{CuCl}_{2} \cdot 2 \mathrm{H}_{2} \mathrm{O}\end{array}$ & & 22.5 & 355 & 10.0 & 5.00 \\
\hline
\end{tabular}

Presented results show influence of changing the concentration of the substances existing in the equilibrium state on the state of multi-phase multi-component system. In proposed experiment these changes are observed only when copper or chlorine ions are introduced into the system. In turn, introducing solid $\mathrm{CuCl}_{2} \cdot 2 \mathrm{H}_{2} \mathrm{O}$ reagent into the system does not cause any noticeable changes.

\section{Conclusion}

The survey results revealed that students have a huge problem with understanding how change of the amount of the solid component influence the efficiency of the Boudouard's reaction. This indicates the need to present students such proposition of the chemical experiment which enables them to better understand the equilibrium state settling in a multi-phase multi-component system. At the same time, it should be emphasized that planning an experiment that can be performed in a school laboratory and meets the requirements of a multi-phase multi-component system in a state of equilibrium is extremely difficult. The proposed in this work experiment is based on the concept of solubility equilibrium, which until 2017 was not taught at the level of secondary school. Preliminary tests carried out on a small group of students attending schools at that time, indicated a better understanding of the subject. Therefore, the proposition of the experiment will be made available to a wider group of students and their teachers. This will allow them to better understand the issues related to the salt solubility, which have been included in the educational requirements of the new core curriculum since 2017. 


\section{References}

[1] Orwat K, Bernard P, Migdał-Mikuli A. Alternative conceptions of common salt hydrolysis among upper-secondary-school students. J Balt Sci Educ. 2017;16:64-76. Available from: http://www.scientiasocialis.1t/jbse/?q=node/547.

[2] Walker PL Jr, Rusinko F Jr, Austin LG. Gas reactions of carbon. Adv Catalysis. 1959;11:133-221. DOI: 10.1016/S0360-0564(08)60418-6 .

[3] Hunt J, Ferrari A, Lita A, Crosswhite M, Ashley B, Stiegman AE. Microwave-specific enhancement of the carbon-carbon dioxide (Boudouard) reaction. J Phys Chem C. 2013;117(51):26871-80. DOI: 10.1021/jp4076965

[4] Quílez-Pardo J, Solaz-Portolés JJ. Students' and teachers' misapplication of le Chatelier's principle: Implications for the teaching of chemical equilibrium. J Res Sci Teach. 1995;32(9):939-57. DOI: 10.1002/tea.3660320906.

[5] Wheeler AE, Kass H. Student misconceptions in chemical equilibrium. Sci Educ. 1978;62:223-32. DOI: 10.1002/sce.3730620212.

[6] Hackling MW, Garnett PJ. Misconceptions of chemical equilibrium. Eur J Sci Educ. 1985;7:205-14. DOI: 10.1080/0140528850070211.

[7] Banerjee AC. Misconceptions of students and teachers in chemical equilibrium. J Sci Educ. 1991;13:487-94. DOI: 10.1080/0950069910130411.

[8] Niaz M. Response to contradiction: conflict resolution strategies used by students in solving problems of chemical equilibrium. J Sci Educ Technol. 2001;10(2):205-11. DOI: 10.1023/A:1009481416943.

[9] Ghirardi M, Marchetti F, Pettinari C, Regis A, Roletto E. Implementing an equilibrium law teaching sequence for secondary school students to learn chemical equilibrium. J Chem Educ. 2015;92:1008-15. DOI: 10.1021/ed500658s.

[10] Kostić VDj, Stankov-Jovanović VP, Sekulić TM, Takači DjB. Visualization of problem solving related to the quantitative composition of solutions in the dynamic GeoGebra environment. Chem Educ Res Pract. 2016;17:120-38. DOI: 10.1039/C5RP00156K.

[11] Gotlib LJ. Relating equilibrium, $\mathrm{pH}$, and solubility product constant: An introductory chemistry laboratory experiment. J Chem Educ. 1990;67(11):937-8. DOI: 10.1021/ed067p937.

[12] Mickey ChD. Chemical equilibrium. J Chem Educ. 1980;57(11):801-4. DOI: 10.1021/ed057p801.

[13] Tang H, Xu M, Zhou X, Zhang Y, Zhao L, Ye G, et al. Acute toxicity and biodistribution of different sized copper nano-particles in rats after oral administration. Mater Sci Eng. 2018;93:649-63. DOI: 10.1016/j.msec.2018.08.032.

[14] Kamble NA. Copper sulphate induced metabolic stress and biochemical composition in aquatic snail Bellamya bengalensis (1). J Chem Biol Phys Sci Sec B. 2019;9(3):447-59. DOI: 10.24214/jcbps.b.9.3.44759.

[15] Srikrishna V, Monteiro-Riviere NA. The effects of sodium hydroxide and hydrochloric acid on isolated perfused skin. In Vitro Toxicol. 1991;4(3):207-15. Available from: https://www.researchgate.net/profile/Nancy_MonteiroRiviere2/publication/285022693_The_effects_of_sodium_hydroxide_and_hydrochloric_acid_on_isolated_p erfused_skin/links/56b3dfe508ae1f8aa4535750/The-effects-of-sodium-hydroxide-and-hydrochloric-acid-onisolated-perfused-skin.pdf.

[16] Kolios L, Striepling E, Kolios G, Dorges J, Sturmer KM, Stuermer EK, et al. The nitric acid burn trauma of the skin. J Plastic Reconstructive Aesthetic Surgery. 2010;63(4):E358-63. DOI: 10.1016/j.bjps.2009.09.001.

[17] Roda E, Barni S, Milzani A, Dalle-Donne I, Colombo G, Coccini T. Single silver nanoparticle instillation induced early and persisting moderate cortical damage in rat kidneys. Int J Mol Sci. 2017;18(10):2115. DOI: 10.3390/ijms18102115.

[18] Panyala NR, Pena-Mendez EM, Havel J. Silver or silver nanoparticles: a hazardous threat to the environment and human health? J Appl Biomed. 2008;6(3):117-29. DOI: 10.32725/jab.2008.015.

[19] Steinborn C, Diegel Ch, Garcia-Kaufer M, Grundemann C, Huber R. Immunomodulatory effects of metal salts at sub-toxic concentrations. J Appl Toxicol. 2017;37:563-72. DOI: 10.1002/jat.3390.

[20] Sousa AB, Maiorka PC, Gonçalves ID, Sá LRM, Górniak SL. Evaluation of effects of prenatal exposure to the cyanide and thiocyanate in wistar rats. Reproductive Toxicol. 2007;23(4):568-77. DOI:10.1016/j.reprotox.2007.01.003.

[21] Ago M, Hayashi T, Ago K, Ogata M. Two fatalities associated with chloroform inhalation. Variation of toxicological and pathological findings. Legal Medicine. 2011;13:156-60. DOI: 10.1016/j.legalmed.2011.01.002. 